\title{
AerGOM, an improved algorithm for stratospheric aerosol extinction retrieval from GOMOS observations - Part 1: Algorithm description
}

\author{
Filip Vanhellemont ${ }^{1}$, Nina Mateshvili ${ }^{1}$, Laurent Blanot ${ }^{3}$, Charles Étienne Robert $^{1}$, Christine Bingen ${ }^{1}$, \\ Viktoria Sofieva $^{2}$, Francis Dalaudier ${ }^{4}$, Cédric Tétard ${ }^{1}$, Didier Fussen ${ }^{1}$, Emmanuel Dekemper $^{1}$, Erkki Kyrölä $^{2}$, \\ Marko Laine ${ }^{2}$, Johanna Tamminen ${ }^{2}$, and Claus Zehner ${ }^{5}$ \\ ${ }^{1}$ Belgisch Instituut voor Ruimte-Aëronomie/Institut d'Aéronomie Spatiale de Belgique, Brussels, Belgium \\ ${ }^{2}$ Finnish Meteorological Institute, Helsinki, Finland \\ ${ }^{3}$ ACRI-ST, Sophia Antipolis, France \\ ${ }^{4}$ Laboratoire Atmosphères, Milieux, Observations Spatiales, Guyancourt, France \\ ${ }^{5}$ ESA-ESRIN, Frascati, Italy
}

Correspondence to: Filip Vanhellemont (filip.vanhellemont@aeronomie.be)

Received: 28 January 2016 - Published in Atmos. Meas. Tech. Discuss.: 5 February 2016

Revised: 24 August 2016 - Accepted: 25 August 2016 - Published: 21 September 2016

\begin{abstract}
The GOMOS instrument on Envisat has successfully demonstrated that a UV-Vis-NIR spaceborne stellar occultation instrument is capable of delivering quality data on the gaseous and particulate composition of Earth's atmosphere. Still, some problems related to data inversion remained to be examined. In the past, it was found that the aerosol extinction profile retrievals in the upper troposphere and stratosphere are of good quality at a reference wavelength of $500 \mathrm{~nm}$ but suffer from anomalous, retrieval-related perturbations at other wavelengths. Identification of algorithmic problems and subsequent improvement was therefore necessary. This work has been carried out; the resulting AerGOM Level 2 retrieval algorithm together with the first data version AerGOMv1.0 forms the subject of this paper. The AerGOM algorithm differs from the standard GOMOS IPF processor in a number of important ways: more accurate physical laws have been implemented, all retrieval-related covariances are taken into account, and the aerosol extinction spectral model is strongly improved. Retrieval examples demonstrate that the previously observed profile perturbations have disappeared, and the obtained extinction spectra look in general more consistent. We present a detailed validation study in a companion paper; here, to give a first idea of the data quality, a worst-case comparison at $386 \mathrm{~nm}$ shows SAGE II-AerGOM correlation coefficients that are up to 1
\end{abstract}

order of magnitude larger than the ones obtained with the GOMOS IPFv6.01 data set.

\section{Introduction}

The sounding of planetary atmospheres by observation of astronomical objects (Sun, Moon, planets, stars) in occultation is a well-established technique. Spaceborne Earth observation instruments such as SAGE II (Chu et al., 1989), SAGE III (Thomason et al., 2010), ORA (Fussen et al., 2001), POAM III (Lucke et al., 1999), ACE-Maestro (Bernath et al., 2005; McElroy et al., 2007) and GOMOS (Bertaux et al., 2010) have clearly demonstrated the possibility to obtain altitude-resolved profiles for a number of atmospheric gaseous species and particles (aerosols, clouds), through the combination of occultation transmittance measurements with a dedicated data inversion algorithm. For obvious reasons, most instruments use the Sun as light source, although the geographical coverage and temporal sampling (at most twice per orbit) is limited. Stellar occultation largely resolves these problems (due to the abundance of stars), however at the cost of a reduced measurement $S / N$ ratio.

The GOMOS instrument and its 10-year quasi-continuous operation can be considered a success. An extensive body 
of papers have been published in the scientific literature that describe the instrument, data processing, and the obtained scientific results for the different atmospheric species; a good overview article has been published by Bertaux et al. (2010). Notwithstanding this success, several problems regarding the instrument and the data processing posed difficulties. Most noteworthy, the imperfect correction of stellar scintillation due to isotropic turbulence (Sofieva et al., 2009) remains a problem, though the associated residual scintillations have been adequately characterized in a statistical analysis (Sofieva et al., 2010). The random nature of these perturbations causes them to disappear after averaging of binned constituent profiles. More important within the context of this paper, aerosol-cloud extinction profile retrievals are of good quality at $500 \mathrm{~nm}$ (Vanhellemont et al., 2008, 2010) but suffer from unphysical perturbations at other wavelengths within the GOMOS spectral range. This problem was already identified earlier (Vanhellemont et al., 2005) but has been left unexamined until now.

From a retrieval point of view, the importance of good aerosol-cloud extinction retrievals lies in the fact that they are intrinsically linked with the retrieval quality of the other species; specifically, upper troposphere-lower stratosphere (UTLS) ozone values are significantly biased due to erroneous aerosol retrievals (Tamminen et al., 2010). Scientifically, good aerosol-cloud extinction observations in the UTLS and stratosphere are of main importance for atmospheric research, in two ways: (1) the Earth radiative budget depends on the optical properties of high-altitude clouds and volcanic sulfate aerosols, and (2) heterogeneous polar ozone chemistry is driven by the presence of polar stratospheric clouds (PSCs), stratospheric aerosols and high-altitude cirrus clouds. A good overview of the scientific significance of aerosols-clouds can be found in the SPARC report (SPARC, 2006).

Improvement of a long-term aerosol-cloud data record such as the one provided by GOMOS is therefore important. The European Space Agency (ESA) has acknowledged this by funding the AerGOM project (Aerosol profile retrieval prototype for GOMOS). Within this project framework, data inversion problems have been studied, solutions have been found, and a new Level 2 algorithm has been developed.

In this article, we summarize the essentials of the GOMOS instrument and its operational data processing algorithm (currently IPF v6.01). Subsequently, we present and justify the specific features that have been changed in the AerGOM code. Finally, the AerGOM aerosol-cloud extinction results are discussed in a qualitative way; a detailed data validation is presented in a companion paper (Robert et al., 2016).

\section{GOMOS and its operational data processor}

\subsection{Instrument and measurement principle}

The GOMOS instrument and measurement principles are described elsewhere (see e.g. Kyrölä et al., 2004; Bertaux et al., 2000, 2010). GOMOS (Global Ozone Monitoring by Occultation of Stars), a UV-Vis-NIR grating spectrometer on board ESA's Envisat satellite, was launched into a sunsynchronous orbit on 1 March 2002. Routine operations started in August 2002, and continued almost uninterruptedly until the end of the mission on 8 April 2012, when contact with the satellite was lost. Using the method of stellar occultation, GOMOS was able to monitor ozone (its main target gas), a number of other trace gases and aerosols, at altitudes that fall within the range from the upper troposphere to the top of the atmosphere. In total, almost a million occultations have been registered by GOMOS during its 10-year mission, roughly half of them in dark limb conditions (local nighttime).

Spectrally, GOMOS is a medium-resolution instrument, designed with ozone monitoring in mind. To obtain ozone profiles from the UTLS (using the Chappuis band) to the upper mesosphere (using the Hartley band), two spectrometers SPA1 and SPA2 were included, covering the UV-visible wavelength range (248-690 $\mathrm{nm}$ ); apart from ozone, this spectral range also allows for the measurement of optical absorption by $\mathrm{NO}_{2}, \mathrm{NO}_{3}$, and the extinction (scattering) by aerosols and air. Other trace gases such as $\mathrm{OClO}$ and $\mathrm{Na}$ are also detectable with specific statistical methods. Furthermore, a spectrometer B1 (SPB1) was added (spectral range $755-774 \mathrm{~nm}$ ), with the purpose of measuring absorption in the $\mathrm{O}_{2}$ A band. Finally, a spectrometer B2 (SPB2) in the nearIR wavelength range (926-954 $\mathrm{nm}$ ) allows the measurement of water vapour. The GOMOS spectrometer characteristics are summarized in Table 1.

It was realized in an early stage of the GOMOS development that stellar scintillation would perturb the measurements considerably. In order to remove this perturbation, GOMOS was equipped with two fast photometers, sampling the blue (473-527 nm) and the red (646-698 nm) spectral domain at a frequency of $1 \mathrm{kHz}$. Apart from the scintillation correction (which was only partially achieved; see further in the text), the time delay between the two photometer signals due to chromatic refraction has been used to obtain altitude profiles of refractive index and temperature.

The basic principle of a stellar occultation experiment is simple: due to orbital motion of the satellite, one observes a star setting behind the Earth horizon; subsequent measurements at different satellite positions therefore sample different atmospheric layers. The altitudinal distribution of atmospheric species can in principle be obtained from this sequence of measurements. The discrimination between different species is of course achieved by measuring in different spectral regions. The duration of a star occultation is deter- 
Table 1. GOMOS spectral bands. The number of pixels for each band and the optically active species are also indicated.

\begin{tabular}{lcrrl}
\hline Spectral band & Wavelength range & No. pixels & Resolution & Major absorbing-scattering species \\
\hline SPA1 \& SPA2 & $248-690 \mathrm{~nm}$ & 1416 & $0.8 \mathrm{~nm}$ & neutral density, $\mathrm{O}_{3}, \mathrm{NO}_{2}, \mathrm{NO}_{3}$, aerosols-clouds \\
SPB1 & $775-774 \mathrm{~nm}$ & 420 & $0.13 \mathrm{~nm}$ & neutral density, $\mathrm{O}_{2}$, aerosols-clouds \\
SPB2 & $926-954 \mathrm{~nm}$ & 500 & $0.13 \mathrm{~nm}$ & neutral density, $\mathrm{H}_{2} \mathrm{O}$, aerosols-clouds \\
\hline
\end{tabular}

mined by its obliquity: an occultation within the orbital plane is vertical and therefore short (about $40 \mathrm{~s}$ ), while observations at an angle with the orbital plane are slant, with a long duration (up to several minutes). It is clear that, for a fixed acquisition time per spectrum, better altitudinal sampling is obtained for long occultation durations.

Finally, it should be mentioned that the measurement $S / N$ ratio is largely determined by the apparent brightness and the temperature of the star; the catalogue used by GOMOS contains objects with visual magnitudes smaller than 4 and temperatures ranging from $3000-30000 \mathrm{~K}$ (i.e. most stellar spectral types). The combined effects of varying obliquities and star characteristics lead to a GOMOS data set that has in a sense an inhomogeneous nature; during data analysis, the variation in altitudinal sampling and $S / N$ ratio has to be taken into account.

\subsection{IPFv6.01 operational data processing}

\subsubsection{Assumptions and initial processing}

It is not the purpose of this paper to describe in detail the GOMOS operational data processing chain. It is nevertheless necessary to give a general overview, in order to highlight the differences with the AerGOM processor further in the text. Detailed descriptions can be found in Kyrölä et al. (2010, 2012). Before the actual data inversion from measurements to geophysical products is performed, downlinked data are formatted, ancillary data are added, the necessary calibration steps are taken and erroneous measurements (e.g. resulting from cosmic ray impacts) are flagged. The contribution of star scintillation to transmittance is estimated from the data of the two photometers and is removed from the spectrometer data. As was mentioned in the introduction, this correction is incomplete since residual scintillation due to isotropic turbulence is not accounted for.

The subsequent Level 2 processing steps are based on a number of assumptions and corrections. (1) The Earth is globally described by a WGS84 reference ellipsoid (NIMA, 1984). Locally, the Earth is approximated by a tangent sphere with a radius equal to the one given by the WGS84 model. (2) Chromatic refraction leads to different tangent points for different wavelengths. A data reinterpolation is performed such that one entire transmittance spectrum is associated with the same tangent point. (3) A correction for refractive dilution is applied. The phenomenon is caused by the altitude gradient of the air refractive index and consists of the spread- ing of light rays (divergence) and an associated decrease in light flux. (4) The finite spectral response of the instrument is taken into account by applying a convolution of theoretical or lab-measured cross sections with the instrument response function. (5) Slant path aerosol optical depth (SAOD) is modelled as a quadratic polynomial of wavelength:

$\tau_{\text {aer }}(\lambda)=\tau_{\text {aer }}\left(\lambda_{\text {ref }}\right)\left[1+c_{1}\left(\lambda-\lambda_{\text {ref }}\right)+c_{2}\left(\lambda-\lambda_{\text {ref }}\right)^{2}\right]$,

with $\lambda_{\text {ref }}$ a reference wavelength of $500 \mathrm{~nm}$, and $\tau_{\text {aer }}\left(\lambda_{\text {ref }}\right), c_{1}$ and $c_{2}$ parameters to be fitted. A quadratic polynomial can fit a wide range of spectral shapes, representing small particles $\left(\tau \sim \lambda^{-4}\right)$, submicron-sized particles (spectra peaking in the visible wavelength range) to large particles ( $\tau=$ constant). (6) The variance of the residual scintillation component in the signals due to isotropic turbulence is taken into account by adding an extra term to the measurement covariance matrix. This so-called full covariance matrix (FCM) method has been described by Sofieva et al. (2010).

The Level 2 inversion is of course based on the BeerLambert law for optical extinction. Furthermore, the entire inversion is divided in two separate subproblems: (1) a spectral inversion from individual transmittance spectra to slant path integrated gas column densities (SGDs; unit: $\mathrm{cm}^{-2}$ ) and aerosol optical depths (SAODs; unitless), and (2) a spatial inversion from these slant path integrated quantities to local gas density and aerosol extinction altitude profiles. The main advantage of this processing chain lies in its numerical efficiency: a large number of measurements (transmittance spectra) are reduced to a small number of slant path integrated quantities in an early stage of the processing.

\subsubsection{Spectral inversion}

The SPB1 and SPB2 spectrometers were primarily meant for oxygen and water vapour measurements. To separate the processing of these two species, it was decided to obtain all other species exclusively from SPA1 and SPA2 data. As an initial step, to avoid correlations between the spectrally similar aerosol and air scattering contributions, the latter is evaluated from ECMWF (European Centre for Medium-Range Weather Forecasts) temperature and pressure forecasts and is removed. The other contributions $\left(\mathrm{O}_{3}, \mathrm{NO}_{2}\right.$ and $\mathrm{NO}_{3}$ SGDs; aerosol SAODs) are obtained by fitting the remaining transmittance $T_{\text {rem }}$ with the Beer-Lambert law (using a Levenberg-Marquardt nonlinear least-squares code). In an early stage of the mission, it was found that the $\mathrm{NO}_{2}$ and $\mathrm{NO}_{3}$ 
SGD retrievals suffered badly from the residual scintillation in the measurements; it was decided to fit both species by making use of their differential spectral features, in a DOASlike manner (differential optical absorption spectroscopy).

At the final iteration of each individual spectral fit, the obtained covariance matrix is evaluated from the forward model Jacobian. It should be emphasized that the fit is performed for every tangent altitude separately; the retrieval covariances between species at different altitudes are therefore equal to zero.

\subsubsection{Spatial inversion}

The obtained SGDs and SAODs are equal to the integral of the local gas densities and aerosol extinction coefficients along the optical path. An appropriate discretization of this integral leads to a linear forward model. For example, the model equations for the column vectors representing altitude profiles for the ozone SGD $\mathrm{N}_{\mathrm{O}_{3}}$ and the $500 \mathrm{~nm}$ aerosol SAOD $\tau_{\text {aer, } 500}$ equal

$\boldsymbol{N}_{\mathrm{O}_{3}}=\mathbf{G} \boldsymbol{n}_{\mathrm{O}_{3}} \quad \boldsymbol{\tau}_{\mathrm{aer}, 500}=\mathbf{G} \boldsymbol{\beta}_{\mathrm{aer}, 500}$,

with the $\boldsymbol{n}_{\mathrm{O}_{3}}$ and $\boldsymbol{\beta}_{\text {aer, } 500}$ vectors representing altitude profiles for the ozone density (molecules $\mathrm{cm}^{-3}$ ) and $500 \mathrm{~nm}$ aerosol extinction $\left(\mathrm{cm}^{-1}\right)$. The square triangular matrix $\mathbf{G}$ contains optical path length contributions: the matrix element $\mathbf{G}_{i j}$ equals the path length for a ray with tangent point radius $r_{i}^{\mathrm{t}}$ through the atmospheric layer centred at $r_{j}^{\mathrm{t}}$.

The spatial inversion then consists of finding a solution for the unknown local altitude profiles ( $\boldsymbol{n}_{\mathrm{O}_{3}}, \boldsymbol{\beta}_{\text {aer, 500 }}$ etc.), using a linear least-squares method, subject to a Tikhonov smoothing constraint. The associated merit function to be minimized reads (for ozone, as an example)

$$
\begin{aligned}
M= & {\left[\boldsymbol{N}_{\mathrm{O}_{3}}-\mathbf{G} \boldsymbol{n}_{\mathrm{O}_{3}}\right]^{T} \mathbf{S}_{N, \mathrm{O}_{3}}^{-1}\left[\boldsymbol{N}_{\mathrm{O}_{3}}-\mathbf{G} \boldsymbol{n}_{\mathrm{O}_{3}}\right] } \\
& +\boldsymbol{n}_{\mathrm{O}_{3}}^{T} \mathbf{L}^{T} \mathbf{L} \boldsymbol{n}_{\mathrm{O}_{3}},
\end{aligned}
$$

where $N_{\mathrm{O}_{3}}$ now represents actual GOMOS-derived SGDs. The diagonal of the slant path covariance matrix $\mathbf{S}_{N, O_{3}}$ contains all variances obtained from the spectral inversion; offdiagonal elements are zero since the spectral inversion occurs separately for each tangent altitude. In the second term, the matrix $\mathbf{L}$ represents a first-difference operator, scaled with altitude- and species-dependent weight factors that tune the profile altitude resolution according to predefined values. This Tikhonov regularization term was introduced to decrease the amplitude of the spurious profile perturbations caused by residual scintillation.

It should be noticed that every individual constituent profile is retrieved independently from the others. This means that spectral inversion covariances between different species are discarded, meaning the algorithm assumes (wrongly) that the obtained SGDs and SAODs after spectral inversion are uncorrelated.

\subsubsection{IPFv6.01 Level 2 data products}

The entire data processing chain finally results in dedicated Level 2 data product files that contain gas SGDs, aerosol SAODs, local gas density and aerosol extinction profiles, together with respective retrieval error estimates. Of specific importance to the subsequent AerGOM discussion in this paper are the so-called residual extinction product files: apart from fit chi-squared statistics and the transmittance fit, they contain the actual transmittance measurements, corrected for refractive dilution and scintillation, and are used as the transmittance data source for the AerGOM inversions.

\subsubsection{Data quality}

With respect to the gaseous Level 2 products, several validation studies have been performed, an overview of which can be found in Bertaux et al. (2010). Initial IPFv6.01 aerosol extinction validation results are presented by Vanhellemont et al. (2010). At wavelengths around $500 \mathrm{~nm}$, good agreement was found within $20 \%$ with SAGE II and SAGE III data (for altitudes from 10 to $25 \mathrm{~km}$ ) and within $10 \%$ with POAM III (from 11 to $22 \mathrm{~km}$ ). At other wavelengths no validation results were published due to the fact that IPFv6.01 GOMOS aerosol extinction profiles are of very poor quality. More specifically, strong oscillations are found in the extinction profiles, and extinction spectra often are very unrealistic. Examples can be found further in Figs. 5, 6 and 7 (discussed below).

\section{The AerGOM algorithm improvements}

\subsection{General approach}

AerGOM shares with the GOMOS processor the same basic separation of the data processing in two distinct steps: a nonlinear spectral inversion, followed by a linear, regularized spatial inversion. There are however several significant differences. (1) To improve accuracy, better equations for the air refractive index and Rayleigh cross section have been used. (2) During spectral inversion, no differential (DOAS) method is applied to obtain $\mathrm{NO}_{2}$ and $\mathrm{NO}_{3}$ SGDs; all gases-aerosols are retrieved together, using their full absorption cross-section-spectral model. This is conceptually simpler; furthermore it ensures that all covariances are retained by the solution. (3) The spectral behaviour of aerosol SAOD is modelled in a better way. (4) The algorithm allows the use of SPB1 and SPB2 pixels, hereby increasing the spectral range and the information content of the solution. (5) The spatial inversion is applied to all species together, hereby making full use of the SGD and SAOD variances and covariances. No information is discarded. And (6) for the spatial inversion, an altitude regularization with a specific scaling is implemented. 


\subsection{Rayleigh scattering by the neutral density (air)}

Equations for the air scattering cross section, approximated for small refractivities (refractive index $m \approx 1$ ), are still commonly found in the literature. For optimal accuracy, we use the exact theoretical result (see e.g. Bodhaine et al., 1999):

$C_{\text {air }}=\frac{24 \pi^{3}}{\lambda^{4} n_{\text {stp }}^{2}}\left(\frac{m_{\mathrm{stp}}(\lambda)^{2}-1}{m_{\mathrm{stp}}(\lambda)^{2}+2}\right)^{2}\left(\frac{6+3 \rho}{6-7 \rho}\right)$,

with $\rho$ the depolarization ratio that takes into account molecular anisotropy, and $n_{\text {stp }}$ the air number density at standard temperature and pressure $\left(P_{\mathrm{stp}}=1013.25 \mathrm{mb}, T_{\mathrm{stp}}=\right.$ $288.15 \mathrm{~K})$. The air refractive index $m_{\text {stp }}$ is evaluated using the equation of Peck and Reeder (1972), which is slightly more accurate than the still widely used Edlén law (Edlén, 1966) (also used in the GOMOS IPF processor). The factor $F_{\text {air }}=(6+3 \rho) /(6-7 \rho)$ is known as the King factor. For air, it is commonly assumed to have a value of 1.06 (Lenoble, 1993). The GOMOS IPFv6.01 processor (Kyrölä et al., 2012) also assumes this value, together with a slightly modified form of Eq. (2). However, $F_{\text {air }}$ depends on wavelength and the actual composition of air, and this should be taken into account. A good overview of this subject was given by Bodhaine et al. (1999). First, we need the partial depolarization of nitrogen and oxygen as given by Bates (1984):

$F_{\mathrm{N}_{2}}(\lambda)=1.034+3.17 \times 10^{-4} \lambda^{-2}$

$F_{\mathrm{O}_{2}}(\lambda)=1.096+1.385 \times 10^{-3} \lambda^{-2}+1.448 \times 10^{-4} \lambda^{-4}$.

Furthermore, Bates (1984) suggested to take $F_{\mathrm{Ar}}=1$, $F_{\mathrm{CO}_{2}}=1.15$ and to ignore other air constituents. Finally, the King factor for air can be calculated as a function of wavelength as

$F_{\text {air }}(\lambda)=\frac{\sum_{i} C_{i} F_{i}(\lambda)}{\sum_{i} C_{i}}$,

where the summation runs over the four most abundant gases, and with concentrations expressed in parts per volume by percent (e.g. use 0.036 for $360 \mathrm{ppm}$ of $\mathrm{CO}_{2}$ ). The concentration values are $C_{\mathrm{N}_{2}}=78.084, C_{\mathrm{O}_{2}}=20.946, C_{\mathrm{Ar}}=0.934$ and $C_{\mathrm{CO}_{2}}=0.036$.

Figure 1 shows calculated King factors in the UV-VisNIR. For illustration, $F_{\text {air }}$ equals 1.063 at $\lambda=250 \mathrm{~nm}$ and 1.047 at $\lambda=1 \mu \mathrm{m}$. The constant value of 1.06 leads to an error in the Rayleigh cross section of respectively 0.3 and $1.2 \%$; the impact on the retrieval of relatively low aerosol extinction coefficients is significant.

The AerGOM algorithm offers the choice to retrieve the neutral air density or to remove the contribution from the measured transmittance $T_{\text {meas }}$ by making use of ECMWF air density profiles, as provided in the GOMOS residual extinction files. The resulting transmission $T$ to be used for the data inversion of all other species is given by

$T\left(\lambda, r^{\mathrm{t}}\right)=\frac{T_{\text {meas }}\left(\lambda, r^{\mathrm{t}}\right)}{T_{\text {air }}\left(\lambda, r^{\mathrm{t}}\right)}$,

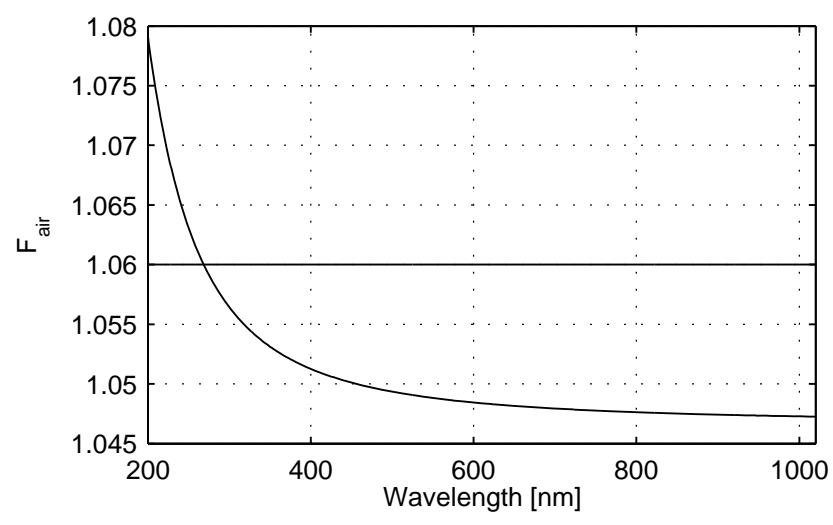

Figure 1. The wavelength-dependent King factor $F_{\text {air }}$ (Bodhaine et al., 1999), together with the commonly used value of 1.06 .

with $T_{\text {air }}$ the transmittance by neutral air having SGD $N_{\text {air }}$ :

$T_{\text {air }}\left(\lambda, r^{\mathrm{t}}\right)=\exp \left(-C_{\text {air }}(\lambda) N_{\text {air }}\left(r^{\mathrm{t}}\right)\right)$.

\subsection{Aerosol extinction modelization}

\subsubsection{Frequently used models}

Prior to the actual inversion of occultation measurements, little is known about the composition, size distribution and morphology of atmospheric particles. The use of Mie theory to model extinction spectra for data inversion purposes is therefore limited. In practice, it is usually preferred to represent aerosol extinction or optical thickness spectra by a smooth analytical function with a small number of parameters (which are to be fitted). The well-known Ångström empirical power law $\left(\beta=A \lambda^{-\alpha}\right)$ is a prime example. It is however not versatile enough; researchers are often forced to make the coefficients $A$ and $\alpha$ wavelength dependent, an approach that seems rather arbitrary. In the current operational GOMOS Level 2 algorithm (IPFv6.01), a quadratic polynomial of wavelength (Eq. 1) is assumed for the aerosol SAOD. In the past, retrieval algorithms for other occultation instruments such as SAGE III (Thomason et al., 2007) and POAM III (Lumpe et al., 2002) were equipped with similar spectral laws for aerosol extinction $\beta_{\text {aer }}$; however they are often expressed as a function of the natural logarithm of wavelength:

$\beta_{\text {aer }}(\lambda)=c_{0}+c_{1} \log (\lambda)+c_{2}(\log (\lambda))^{2}$.

The formalism can of course be extended to general polynomials of functions of wavelength. As an example, quadratic polynomials of inverse wavelength $\left(\lambda^{-1}\right)$ have been found to model realistic extinction spectra quite well (Vanhellemont et al., 2006). 


\subsubsection{AerGOM aerosol spectral law implementation}

Inspecting Eq. (1), we see that, among the three fit parameters, only $\tau_{\text {aer }}\left(\lambda_{\text {ref }}\right)$ represents a physical quantity. There are two reasons for why this formalism is not optimal: (1) the three coefficients $\tau_{\text {aer }}, c_{1}$ and $c_{2}$ have a different unit and magnitude, giving rise to scaling problems during numerical inversion, and (2) during the spatial inversion from SAOD to local extinction values, it is not clear whether or not altitude regularization constraints on the coefficients $c_{1}$ and $c_{2}$ are meaningful. The GOMOS IPFv6.01 algorithm, making use of this implementation, avoids the second point by inverting only $\tau_{\text {aer }}\left(\lambda_{\text {ref }}\right)$ with altitude regularization. It is the main reason why GOMOS aerosol extinction profiles exhibit strong oscillations for other wavelengths than $\lambda_{\text {ref }}=500 \mathrm{~nm}$.

The AerGOM solution consists of a fairly simple mathematical reformulation. The SAOD, modelled as an $m$ th degree polynomial of a function of wavelength $f(\lambda)$, can be expressed as a Lagrangian interpolation formula between a number of discrete SAOD values $\tau\left(\lambda_{i}\right)$ at different wavelengths:

$\tau_{\mathrm{aer}}(\lambda)=\sum_{i=1}^{m+1} q_{i}(\lambda) \tau_{\mathrm{aer}}\left(\lambda_{i}\right)$,

with spectral base functions

$q_{i}(\lambda)=\prod_{j \neq i}^{m+1} \frac{f(\lambda)-f\left(\lambda_{j}\right)}{f\left(\lambda_{i}\right)-f\left(\lambda_{j}\right)}$.

For example, a quadratic polynomial of inverse wavelength is specified by the choice $m=2$ and three spectral base functions:

$q_{i}(\lambda)=\frac{\left(\lambda^{-1}-\lambda_{j}^{-1}\right)\left(\lambda^{-1}-\lambda_{k}^{-1}\right)}{\left(\lambda_{i}^{-1}-\lambda_{j}^{-1}\right)\left(\lambda_{i}^{-1}-\lambda_{k}^{-1}\right)}$,

with $\lambda_{i}, \lambda_{j}$ and $\lambda_{k}$ three different wavelengths that have to be specified in advance. Examples of base functions are given in Fig. 2. The spectral behaviour of aerosols is now parametrized by three SAOD values, having the same order of magnitude and a direct physical meaning.

\subsubsection{Aerosol spectral model: choice based on data}

The actual choice of aerosol spectral law should be based on its ability to model realistic spectra for particle populations that are found in the atmosphere. By fitting measured or measurement-derived aerosol extinction spectra with a number of candidate analytical extinction models, it is possible to single out one of these models that can be used in the AerGOM retrieval algorithm. We therefore consulted particle size data derived from measurements that were performed by satellite instruments (SAGE II, CLAES and POAM), field campaign results (APE-THESEO; Airborne Platform

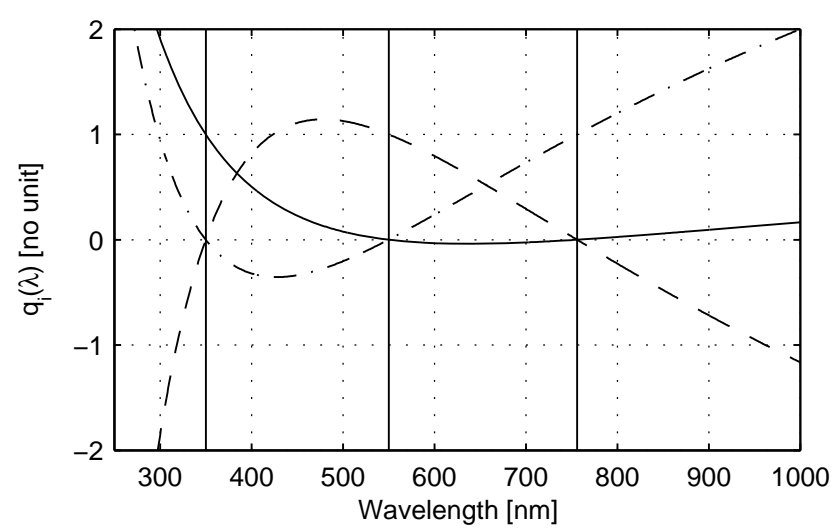

Figure 2. Aerosol spectral functions $q_{1}(\lambda)$ (solid), $q_{2}(\lambda)$ (dashed) and $q_{3}(\lambda)$ (dash-dot) for a quadratic polynomial of inverse wavelength. The three predefined wavelengths are $\lambda_{1}=350 \mathrm{~nm}, \lambda_{2}=$ $550 \mathrm{~nm}$, and $\lambda_{3}=756 \mathrm{~nm}$ (vertical lines).

for Earth observation - contribution to the Third European Stratospheric Experiment on Ozone; Stefanutti et al., 2004) and many lidar and in situ instruments (Deshler et al., 2003). Measurements of different particle types were considered: (1) stratospheric sulfuric acid droplets, (2) polar stratospheric clouds (NAT: nitric acid trihydrate; STS: supercooled ternary solution; water ice) and (3) cirrus and subvisual cirrus clouds.

Starting from published values of microphysical parameters (typically lognormal parameters for total number density, mode radius and distribution width), we simulated extinction spectra with a Mie code (assuming spherical particles). This of course requires the wavelength-dependent refractive index of the particles under consideration. For pure-water ice these can be directly interpolated from tabulated data that were published by Warren (1984). The other particle types that are to be expected consist of binary and ternary solutions of sulfuric or nitric acid, of which the weight percentages (mainly driven by temperature) were obtained from theory: polar winter temperatures (Meilinger et al., 1995) as well as common stratospheric temperatures (Carslaw et al., 1997) were considered. From these weight percentages, the refractive index was calculated with a code, published by Krieger et al. (2000), which is based on a generalized LorentzLorenz equation for the refractive index. The various ways we calculated the refractive index for commonly encountered particle types in GOMOS data are summarized in Table 2.

Finally, the obtained spectra were fitted with a range of candidate spectral laws. Extinction and the logarithm of extinction were fitted with second- and third-degree polynomials of $\lambda, 1 / \lambda$ and $\log (\lambda)$. After comparison of the fit quality, the second-degree polynomial of inverse wavelength was singled out as a good versatile model for particle extinction spectra for the bulk of GOMOS measurements.

As an example, we used the SAGE II-CLAES stratospheric aerosol climatology of Bauman et al. (2003) and converted a few of their values for effective radius $R_{\text {eff }}$, mode 
Table 2. The types of particles that are to be expected in the GOMOS data, with characteristics. The methods used to estimate composition (from temperature) and refractive index are also indicated.

\begin{tabular}{llll}
\hline Type & State/morphology/composition & Weight percentage & Refractive index \\
\hline Background & Liquid/spherical, $\mathrm{H}_{2} \mathrm{O} / \mathrm{H}_{2} \mathrm{SO}_{4}$ & Carslaw et al. (1997) & Krieger et al. (2000) \\
Volcanic & Liquid/spherical, $\mathrm{H}_{2} \mathrm{O} / \mathrm{H}_{2} \mathrm{SO}_{4}$ & Carslaw et al. (1997) & Krieger et al. (2000) \\
Cirrus & Solid/crystalline, $\mathrm{H}_{2} \mathrm{O}$ & - & Warren (1984) \\
NAT PSC & Solid/amorphous, $\mathrm{HNO}_{3} / \mathrm{H}_{2} \mathrm{O}$ & Meilinger et al. (1995) & Krieger et al. (2000) \\
STS PSC & Liquid/spherical, $\mathrm{H}_{2} \mathrm{O} / \mathrm{H}_{2} \mathrm{SO}_{4} / \mathrm{HNO}_{3}$ & Meilinger et al. (1995) & Krieger et al. (2000) \\
Ice PSC & Solid/crystalline, $\mathrm{H}_{2} \mathrm{O}$ & - & Warren (1984) \\
\hline
\end{tabular}

Table 3. Stratospheric aerosols: lognormal particle size distribution parameters $r_{\mathrm{m}}$ (mode radius) and $\sigma$ (mode width), and aerosol extinction $\beta_{\text {aer }}$ at $525 \mathrm{~nm}$, representative of the period just before and after the Pinatubo eruption, at two different altitudes, in the 30 $50^{\circ} \mathrm{N}$ latitude band. The data were derived from Figs. 4, 8 and 11 of Bauman et al. (2003). A few calculated refractive indices are also given.

\begin{tabular}{lllr}
\hline $\begin{array}{l}\text { Number } \\
\text { in Fig. } 3\end{array}$ & $\begin{array}{l}r_{\mathrm{m}} \\
(\mu \mathrm{m})\end{array}$ & $\sigma$ & $\begin{array}{l}\beta_{\text {aer }}(525 \mathrm{~nm}) \\
\left(10^{-3} \mathrm{~km}^{-1}\right)\end{array}$ \\
\hline \multicolumn{3}{l}{ Altitude $=$} & $18.5 \mathrm{~km}, T=217 \mathrm{~K}, \mathrm{H}_{2} \mathrm{SO}_{4}$ weight perc. $=78 \%$ \\
Refractive & index $=1.47(400 \mathrm{~nm}), 1.46(600 \mathrm{~nm})$ & 1 \\
\hline 1 & 0.075 & 1.4 & 1 \\
2 & 0.084 & 1.8 & 2 \\
3 & 0.063 & 2.2 & 4 \\
4 & 0.169 & 1.8 & 5 \\
5 & 0.288 & 1.6 & 5 \\
6 & 0.181 & 2.0 & \\
\hline
\end{tabular}

Altitude $=26.5 \mathrm{~km}, T=223 \mathrm{~K}, \mathrm{H}_{2} \mathrm{SO}_{4}$ weight perc. $=82 \%$ Refractive index $=1.48(400 \mathrm{~nm}), 1.47(600 \mathrm{~nm})$

\begin{tabular}{lrrr}
\hline 7 & 0.092 & 1.2 & 0.05 \\
8 & 0.151 & 1.4 & 0.4 \\
9 & 0.127 & 1.8 & 2 \\
10 & 0.230 & 1.6 & 4 \\
11 & 0.288 & 1.6 & 8 \\
12 & 0.346 & 1.6 & 12 \\
\hline
\end{tabular}

width $\sigma$ and $525 \mathrm{~nm}$ aerosol extinction $\beta_{\text {aero }}$ (respectively Figs. 4,8 and 11 in the paper) to the values in Table 3. Furthermore, stratospheric in situ data derived from impactor samples collected onboard an ER-2 aircraft (Pueschel et al., 1994) were used (see Table 4). In both cases, we assumed US76 temperatures at the considered altitudes and derived corresponding $\mathrm{H}_{2} \mathrm{SO}_{4}$ weight percentages with the method of Carslaw et al. (1997). Refractive indices were obtained with the method of Krieger et al. (2000). Finally, we calculated the extinction spectra in Fig. 3 with a Mie code. Also shown are the fits with the quadratic polynomial of inverse wavelength; the correspondence is quite good.

\subsection{Transmittance data}

As mentioned before, the GOMOS IPFv6.01 processor uses exclusively SPA1 and SPA2 data for the retrieval of $\mathrm{O}_{3}, \mathrm{NO}_{2}$, $\mathrm{NO}_{3}$ and aerosol extinction data products, while the SPB1 and SPB2 data are reserved for the retrieval of $\mathrm{O}_{2}$ and $\mathrm{H}_{2} \mathrm{O}$. With respect to aerosol retrievals, this is regrettable; at longer wavelengths, the relative contribution of aerosol extinction is stronger (in the lower atmosphere) due to weaker air scattering. Furthermore, anticipating future research, particle size distribution retrievals improve if the spectral range is larger (Fussen et al., 2002).

We therefore studied the possibility of exploiting SPB1 and SPB2 data in the AerGOM processor. Of course, care needs to be taken to avoid the use of wavelengths at which $\mathrm{O}_{2}$ and $\mathrm{H}_{2} \mathrm{O}$ absorb. Figure 4 shows one way of doing this. It is intuitively clear that the spectral ranges to the left and the right of the $\mathrm{O}_{2}$ absorption band in the SPB1 data are useful to extract aerosol extinction. On the other hand, it is far less obvious to define SPB2 spectral pixels that are free of $\mathrm{H}_{2} \mathrm{O}$ absorption lines. The importance of these spectral regions is nevertheless clear when we observe the transmittance altitude profiles in the right panel of Fig. 4; in the lower stratosphere and upper troposphere (our main region of interest) a very useful range of transmittance is present in the SPB1 and SPB2 spectral bands while the SPA transmittance values have almost dropped to zero. For flexibility, the AerGOM processor offers the possibility to select SPA/SPB1/SPB2 spectral pixels at will. Due to the difficulty of finding SPB2 spectral pixels without $\mathrm{H}_{2} \mathrm{O}$ absorption, and the fact that Aer$\mathrm{GOM}$ is at present not able to perform $\mathrm{H}_{2} \mathrm{O}$ retrievals, SPB2 data are currently not selected for the retrievals. This situation will likely change for future AerGOM data versions.

\subsection{AerGOM spectral inversion}

In comparison with the GOMOS processor, the AerGOM spectral inversion is conceptually much simpler. No separate differential method is used to derive $\mathrm{NO}_{2}$ and $\mathrm{NO}_{3}$ SGDs. Instead, contributions from all molecular/particulate species to the optical extinction are included in the Beer-Lambert 
Table 4. Stratospheric aerosols: bimodal lognormal particle size distribution parameters $N_{0}$ and $N_{1}$ (aerosol total number density), $r_{\mathrm{m} 0}$ and $r_{\mathrm{m} 1}$ (mode radius), and $\sigma_{0}$ and $\sigma_{1}$ (mode width), representative of the period just before and after the Pinatubo eruption. The data were obtained from impactor samples on an ER-2 aircraft and were published by Pueschel et al. (1994) (Table 1a). For optical calculations, we used $\mathrm{H}_{2} \mathrm{SO}_{4}$ weight percentage of $78 \%$, corresponding to a temperature of $217 \mathrm{~K}$. Examples of refractive indices: 1.47 (400 nm), 1.46 $(600 \mathrm{~nm})$.

\begin{tabular}{lrrrrrrrrrr}
\hline $\begin{array}{l}\text { Number } \\
\text { in Fig. 3 }\end{array}$ & Date & Latitude & Longitude & $\begin{array}{l}\text { Altitude } \\
(\mathrm{km})\end{array}$ & $\begin{array}{l}N_{0} \\
\left(\mathrm{~cm}^{-3}\right)\end{array}$ & $\begin{array}{l}r_{\mathrm{m} 0} \\
(\mu \mathrm{m})\end{array}$ & $\sigma_{0}$ & $\begin{array}{l}N_{1} \\
\left(\mathrm{~cm}^{-3}\right)\end{array}$ & $\begin{array}{l}r_{\mathrm{m} 1} \\
(\mu \mathrm{m})\end{array}$ & $\sigma_{1}$ \\
\hline 13 & 28 Feb 1991 & $40^{\circ} \mathrm{N}$ & $123^{\circ} \mathrm{W}$ & 18.3 & 1.0 & 0.1 & 1.8 & 0 & 0 & 0 \\
14 & 14 Oct 1991 & $39^{\circ} \mathrm{N}$ & $123^{\circ} \mathrm{W}$ & 20.7 & 2.8 & 0.11 & 1.4 & 1.9 & 0.30 & 1.5 \\
15 & 14 Oct 1991 & $66^{\circ} \mathrm{N}$ & $123^{\circ} \mathrm{W}$ & 18.5 & 2.8 & 0.13 & 1.6 & 0.6 & 0.55 & 1.2 \\
16 & 2 Nov 1991 & $41^{\circ} \mathrm{N}$ & $107^{\circ} \mathrm{W}$ & 20.2 & 2.1 & 0.09 & 1.2 & 1.2 & 0.35 & 1.6 \\
17 & 20 Mar 1992 & $48^{\circ} \mathrm{N}$ & $71^{\circ} \mathrm{W}$ & 20.0 & 0.4 & 0.09 & 1.5 & 1.8 & 0.46 & 1.7 \\
\hline
\end{tabular}
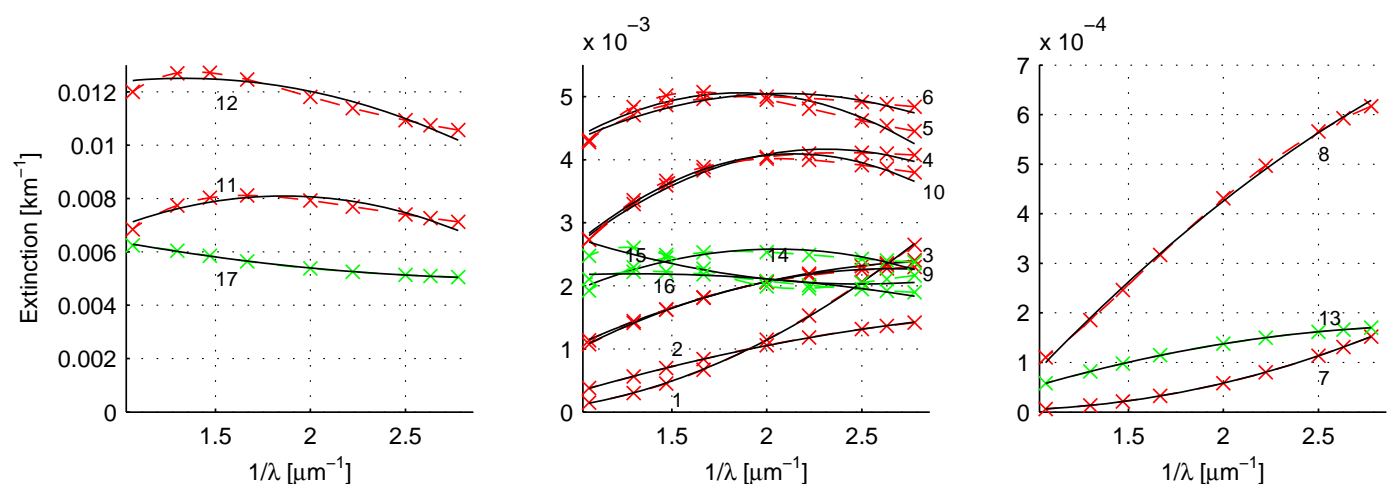

Figure 3. Measured and fitted stratospheric sulfate aerosol extinction spectra for different aerosol size distributions. The three panels each cover a different extinction magnitude range. Crosses with dashed lines represent values derived from a SAGE II-CLAES climatology (red) and in situ impactor measurements (green). Also shown is the fit with the second-order polynomial of inverse wavelength (black solid lines). The numbers on the plots correspond to the data in Tables 3 and 4.
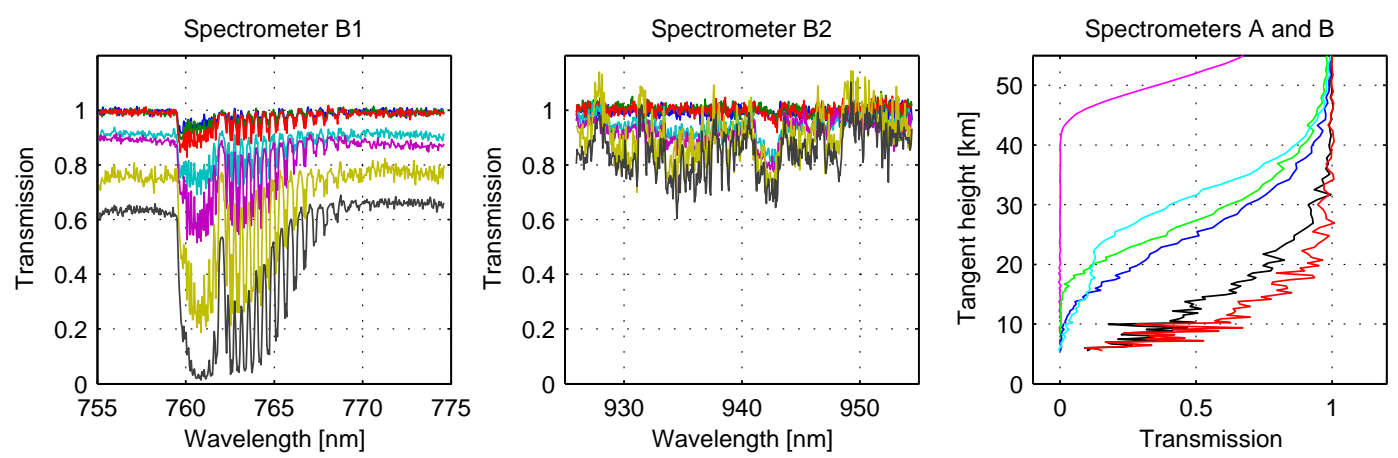

Figure 4. Examples of spectra (27 September $2004,21.17^{\circ} \mathrm{S}, 48.62^{\circ} \mathrm{E}$ ) for SPB1 (left) and SPB2 (middle) at tangent altitudes of (roughly) 15, 20, 25, 30, 35, 40 and $45 \mathrm{~km}$ (from bottom to top). Right panel: tangent altitude profiles of GOMOS transmittance for spectrometer A: 300 (magenta), 400 (green), 500 (blue), $600 \mathrm{~nm}$ (cyan); spectrometer B1 (black); B2 (red); the B1 and B2 profiles are very rough estimates of what can be expected; they are median values of the wings left and right of the B1 oxygen band, and the entire B2 spectrum respectively.

forward model, which now reads

$\left.T\left(r^{\mathrm{t}}, \lambda\right)=\exp \left[-\sum_{i} C_{i}(\lambda) N_{i}\left(r^{\mathrm{t}}\right)-\sum_{j} q_{j}(\lambda) \tau_{\mathrm{aer}}\left(r^{\mathrm{t}}, \lambda_{j}\right)\right)\right]$.

The first term in the exponent indicates a summation over all gaseous species $\left(\mathrm{O}_{3}, \mathrm{NO}_{2}\right.$ and $\mathrm{NO}_{3}$, if Rayleigh scattering is removed before inversion), while the second term expresses our new aerosol SAOD formalism (Eq. 3). Once again, a nonlinear Levenberg-Marquardt inversion is performed at every tangent point individually, and a complete covariance matrix $\mathbf{S}$ is obtained that contains the retrieval dependencies between all SGDs and SAODs. 


\subsection{AerGOM spatial inversion}

AerGOM performs a spatial inversion on all species simultaneously. This allows the full use of all spectral inversion covariances between different species, which are discarded by the GOMOS IPFv6.01 processor. The importance of these covariances is crucial: using them in the spatial inversion significantly reduces the volume of the state space of possible solutions.

Spatial inversion of all species simultaneously is achieved by expressing the forward model as

$N_{\text {tot }}=\mathbf{G}_{\text {tot }} n_{\text {tot }}$,

with $\boldsymbol{N}_{\text {tot }}$ a column vector containing all gas SGDs and aerosol SAODs obtained from the spectral inversion, $\boldsymbol{n}_{\text {tot }}$ a column vector containing all local gas densities and aerosol extinction coefficients, and $\mathbf{G}_{\text {tot }}$ a matrix containing optical path lengths, similar to the ones that were discussed in Sect. 2.2.3.

Also here, to control the smoothness of the altitude profiles, the linear inversion is performed with a Tikhonov regularization constraint. The merit function $M$ to be minimized reads

$$
\begin{aligned}
M= & {\left[\boldsymbol{N}_{\mathrm{tot}}-\mathbf{G}_{\mathrm{tot}} \boldsymbol{n}_{\mathrm{tot}}\right]^{T} \mathbf{S}_{N, \text { tot }}^{-1}\left[\boldsymbol{N}_{\mathrm{tot}}-\mathbf{G}_{\mathrm{tot}} \boldsymbol{n}_{\mathrm{tot}}\right] } \\
& +\boldsymbol{n}_{\mathrm{tot}}^{T} \mathbf{H}_{\mathrm{tot}} \boldsymbol{n}_{\mathrm{tot}},
\end{aligned}
$$

with $\boldsymbol{N}_{\text {tot }}$ here representing actual GOMOS-derived SGDs and SAODs, $\mathbf{S}_{N \text {, tot }}$ the associated total covariance matrix that is formed by stacking together all covariance matrices (including off-diagonal elements) obtained from the spectral inversion, and $\mathbf{H}_{\text {tot }}$ the Tikhonov smoothing operator. The solution is given by

$\boldsymbol{n}_{\text {tot }}=\mathbf{S}_{n, \text { tot }} \mathbf{G}_{\text {tot }}^{T} \mathbf{S}_{N \text {, tot }}^{-1} \boldsymbol{N}_{\text {tot }}$,

with solution covariance matrix

$\mathbf{S}_{n, \text { tot }}=\left(\mathbf{G}_{\mathrm{tot}}^{T} \mathbf{S}_{N, \text { tot }}^{-1} \mathbf{G}_{\mathrm{tot}}+\mathbf{H}_{\mathrm{tot}}\right)^{-1}$.

Care should be taken to properly scale $\mathbf{H}_{\text {tot }}$, since atmospheric species profiles span several orders of magnitude. A natural scaling is provided by the unconstrained least-squares covariance matrix of the solution (obtained by putting the Tikhonov term in Eq. 4 to zero):

$\mathbf{S}_{n, \text { tot, LS }}=\left(\mathbf{G}_{\mathrm{tot}}^{T} \mathbf{S}_{N, \text { tot }}^{-1} \mathbf{G}_{\mathrm{tot}}\right)^{-1}=\mathbf{D R D}$,

where we have also expressed the covariance matrix in terms of the diagonal standard deviation matrix $\mathbf{D}$ and the correlation matrix $\mathbf{R}$. We then choose the regularization operator as follows:

$\mathbf{H}_{\mathrm{tot}}=\left(\mathbf{L}_{\mathrm{tot}} \mathbf{D}^{-1}\right)^{T}\left(\mathbf{L}_{\mathrm{tot}} \mathbf{D}^{-1}\right)$,
Table 5. Summary of the main configuration settings for the AerGOM v1.0 processing.

\begin{tabular}{ll}
\hline Implementation & Setting \\
\hline Retrieved species & $\mathrm{O}_{3}, \mathrm{NO}_{2}, \mathrm{NO}_{3}$, aerosols-clouds \\
Full covariance matrix $(\mathrm{FCM})$ & no \\
Top of atmosphere & $120 \mathrm{~km}$ \\
Rayleigh scattering & From ECMWF $(P>1 \mathrm{hPa})$ \\
& and MSIS90 $(P<1 \mathrm{hPa})$ \\
$\tau_{\text {aer }}(\lambda)$ & Quadratic polynomial of $1 / \lambda$ \\
$\tau_{\text {aer }}$ parametrized at & 350,550, and $756 \mathrm{~nm}$ \\
Spectral windows selected & $248.1-685 \mathrm{~nm}(\mathrm{SPA})$ \\
& $755-759.3 \mathrm{~nm}(\mathrm{SPB} 1)$ \\
& $770-775 \mathrm{~nm}(\mathrm{SPB} 1)$ \\
Tikhonov parameters $\mu_{i}$ & Gases: 0.1 \\
& Aerosol extinction: 3 \\
\end{tabular}

where it is understood that $\mathbf{L}_{\text {tot }}$ is a composite operator, consisting of several first-difference operators $\mathbf{L}_{i}$ (one for each gas density and aerosol extinction profile), each one of them multiplied with its own regularization parameter $\mu_{i}$. The functionality of the applied scaling becomes clear when we rewrite the covariance matrix of the regularized solution (Eq. 4):

$\mathbf{S}_{n, \text { tot }}=\mathbf{D}\left(\mathbf{R}^{-1}+\mathbf{L}_{\text {tot }}^{T} \mathbf{L}_{\mathrm{tot}}\right)^{-1} \mathbf{D}$.

We then compare it with the least-squares covariance matrix (Eq. 5): the altitude smoothing operates directly on the correlation matrix $\mathbf{R}$, which is properly scaled by definition.

\subsection{Results}

\subsubsection{AerGOM processing}

The entire 10-year GOMOS data set has been processed with the AerGOM algorithm. The specific configuration that was chosen, taking into account the required data quality and processing speed, is presented in Table 5. Notice specifically that for this first tentative processing the FCM method was not used because it is computationally expensive. Furthermore, the Rayleigh contribution was not retrieved but computed and removed, using meteorological data together with the Rayleigh cross section (Eq. 2). Finally, SPB2 data were not used (since all wavelengths are affected by water vapour, a species that is currently not retrieved by AerGOM), while only the SPB1 spectral pixels outside the $\mathrm{O}_{2}$ absorption band were exploited.

By launching several batch processes in parallel, we were able to process the entire dark limb GOMOS data set in two days. The resulting AerGOM v1.0 data set (profiles for gas SGD and local densities, aerosol SAOD and extinction coefficients, retrieval errors, ancillary data and inversion statistics) occupies about $74 \mathrm{~GB}$ of disk space. 

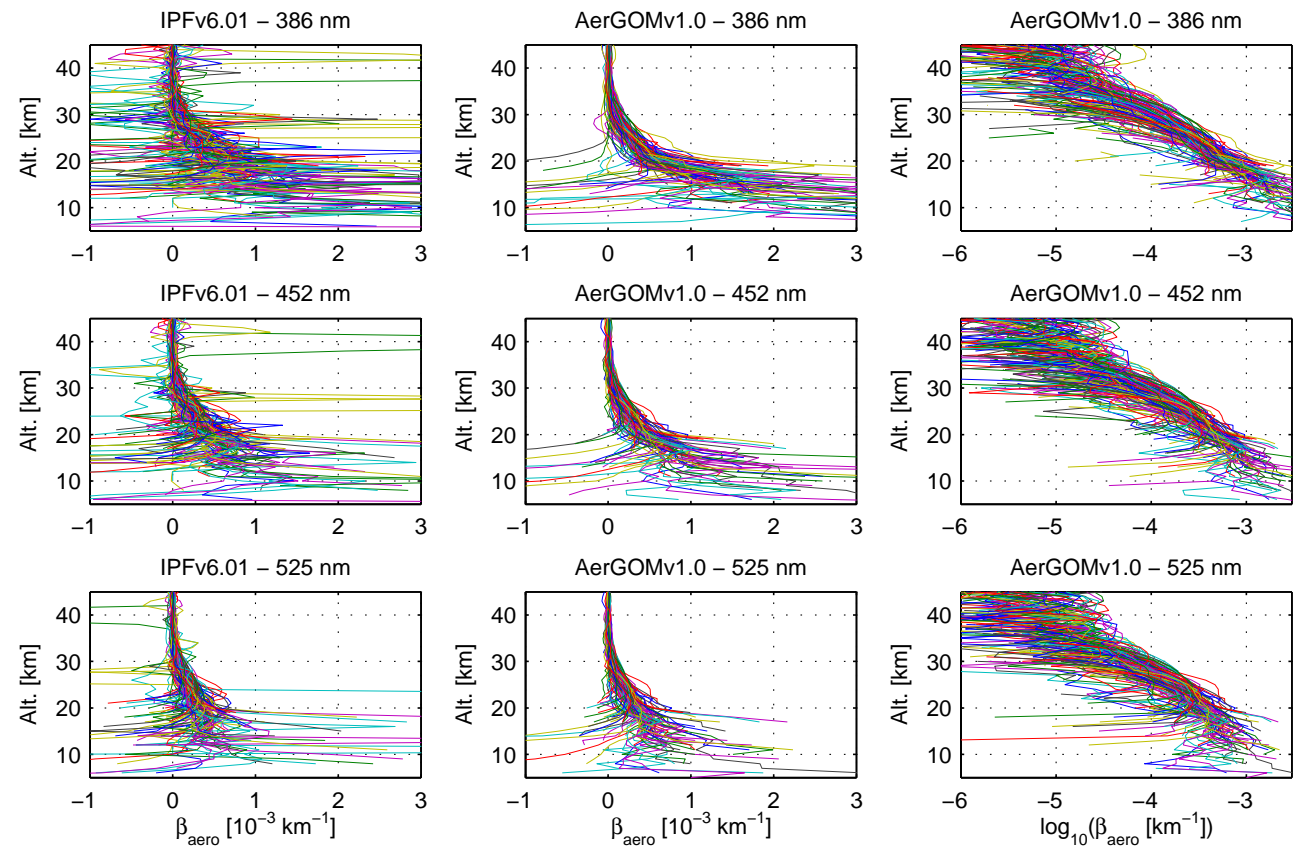

Figure 5. A set of 115 randomly chosen GOMOS aerosol extinction profiles, evaluated at three wavelengths, for the two algorithms. Left column: IPFv6.01; middle column: AerGOM v1.0. Right column: AerGOM v1.0, base 10 logarithm of aerosol extinction.
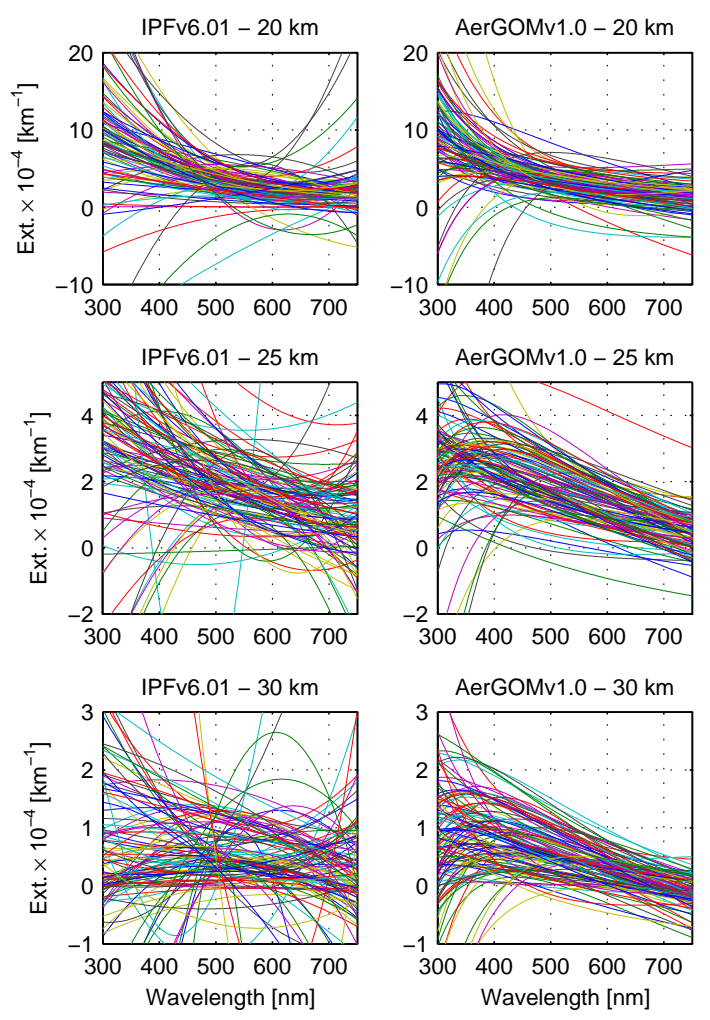

Figure 6. Aerosol extinction spectra at altitudes 20, 25 and $30 \mathrm{~km}$. The same data set as in Fig. 5 was used. Left column: IPFv6.01; right column: AerGOM v1.0.

\subsubsection{A first look at the AerGOM results}

A detailed validation will be presented in a companion paper (Robert et al., 2016). Here, we will present a qualitative evaluation of the obtained AerGOM data by comparison with the IPFv6.01 products; visual inspection is sufficient to demonstrate the improvement.

Figure 5 shows an ensemble of 115 randomly chosen aerosol extinction profiles (in a window from April 2002 to April 2005, between $60^{\circ} \mathrm{S}$ and $60^{\circ} \mathrm{N}$ ), evaluated at three wavelengths $(386,452$ and $525 \mathrm{~nm}$ ) using the assumed quadratic law. Clearly visible are the IPFv6.01 spurious oscillations, which increase in amplitude for wavelengths farther away from the reference wavelength of $500 \mathrm{~nm}$. As was anticipated, the situation improves dramatically for the AerGOM data.

We also observe a larger spread of the aerosol extinction profiles at lower altitudes (below about $20 \mathrm{~km}$ ) for both retrieval algorithms. The most important reason for this increased variability is not related to retrieval methodology but to the limited signal-to-noise $(S / N)$ ratio of a stellar occultation experiment. Indeed, at lower altitudes, stronger optical extinction occurs due to longer optical paths and denser atmospheric layers; measured signals become comparable to the instrument noise levels. The altitude region where this happens depends of course on the stellar properties (mainly magnitude). Furthermore, the presence of clouds in the troposphere contributes to the increased variability that is observed. 

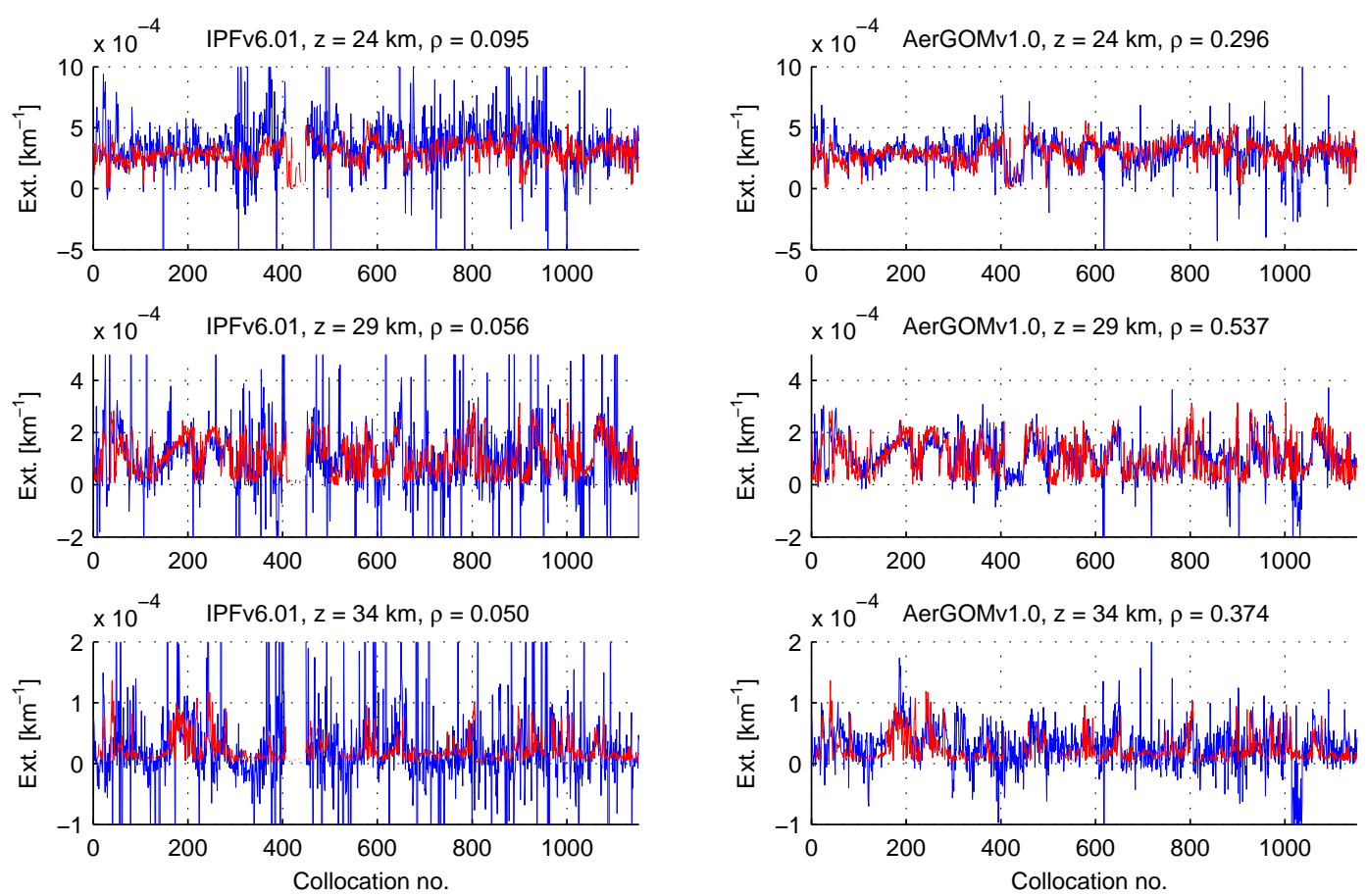

Figure 7. A chronological series of aerosol extinction values at $386 \mathrm{~nm}$, for 1152 GOMOS (blue) and SAGE II (red) collocations. From top to bottom: altitude $=24,29$ and $34 \mathrm{~km}$. Left column: IPFv6.01; right column: AerGOM v1.0. Correlation coefficients $\rho$ are also indicated in the subplot titles.

The same set of 115 profiles was used for the plots in Fig. 6, showing aerosol extinction spectra in the wavelength range from 300 to $750 \mathrm{~nm}$ at three different altitudes. Also here, much more consistent behaviour with fewer oscillations is exhibited by the AerGOM v1.0 data set. Notice the increased variability of extinction values at short wavelengths (below $400 \mathrm{~nm}$ ), reflecting the larger retrieval errors due to the small aerosol-molecular extinction ratio at these wavelengths. In particular, the spectral maxima between 300 and $400 \mathrm{~nm}$ should not be considered as physical features but result from the lack of instrument sensitivity to aerosols.

The correspondence between the IPFv6.01 and AerGOM data sets with SAGE II results is illustrated in Fig. 7. Shown are chronologically ordered aerosol extinction values at $386 \mathrm{~nm}$ for collocated GOMOS-SAGE II occultation events (within a window of $500 \mathrm{~km}$ and $12 \mathrm{~h}$ ), at three different altitudes spanning the middle stratosphere. On average, the IPFv6.01 data follow the SAGE II values closely but are very noisy. The amplitude of this noise decreases strongly in the AerGOM v1.0 series, and the overall agreement between AerGOM and SAGE II values seems to be very good. This is confirmed when we inspect the correlation coefficients (also given in Fig. 7), which are significantly larger for the SAGE II-AERGOM case, even up to 1 order of magnitude at $29 \mathrm{~km}$. It should be mentioned that aerosol extinction retrievals at the small wavelength of $386 \mathrm{~nm}$ are of limited quality due to the much larger contribution of neutral density Rayleigh scattering to the total extinction. For example, typical SAGE II aerosol extinction retrieval errors are $22 \%(24 \mathrm{~km}), 32 \%(29 \mathrm{~km})$ and $45 \%(34 \mathrm{~km})$, with similar or larger numbers for GOMOS-AerGOM retrievals, depending on the magnitude and temperature of the used star. This limited aerosol information content manifests itself in correlation coefficients that are still very modest. Nevertheless, the much higher SAGE II-AerGOM coefficients demonstrate the improvement with respect to IPFv6.01.

Coming back to the aerosol extinction spectra in Fig. 6 we observe that, while the AerGOM results look more consistent than the IPF ones, quite a large spectral variability (roughly speaking, the slope of the spectra with respect to wavelength) is still present. At first sight, this seems to suggest a strong variability of particle size distributions. This contradicts the fact that the considered period (2002-2005) was remarkably stable and free from major volcanic eruptions (only background aerosols). However, the observed spectral variation is just caused by instrument noise, and the associated extinction error bars are quite large. To demonstrate this, we have fitted an Ångström power law to the 386, 425 and $525 \mathrm{~nm}$ AerGOM extinction values (evaluated at these wavelengths using the assumed quadratic polynomial of inverse wavelength), as well as the SAGE II values for comparison:

$\log \left(\beta_{\text {aer }}(\lambda)\right)=\log A-\alpha \log (\lambda)$ 

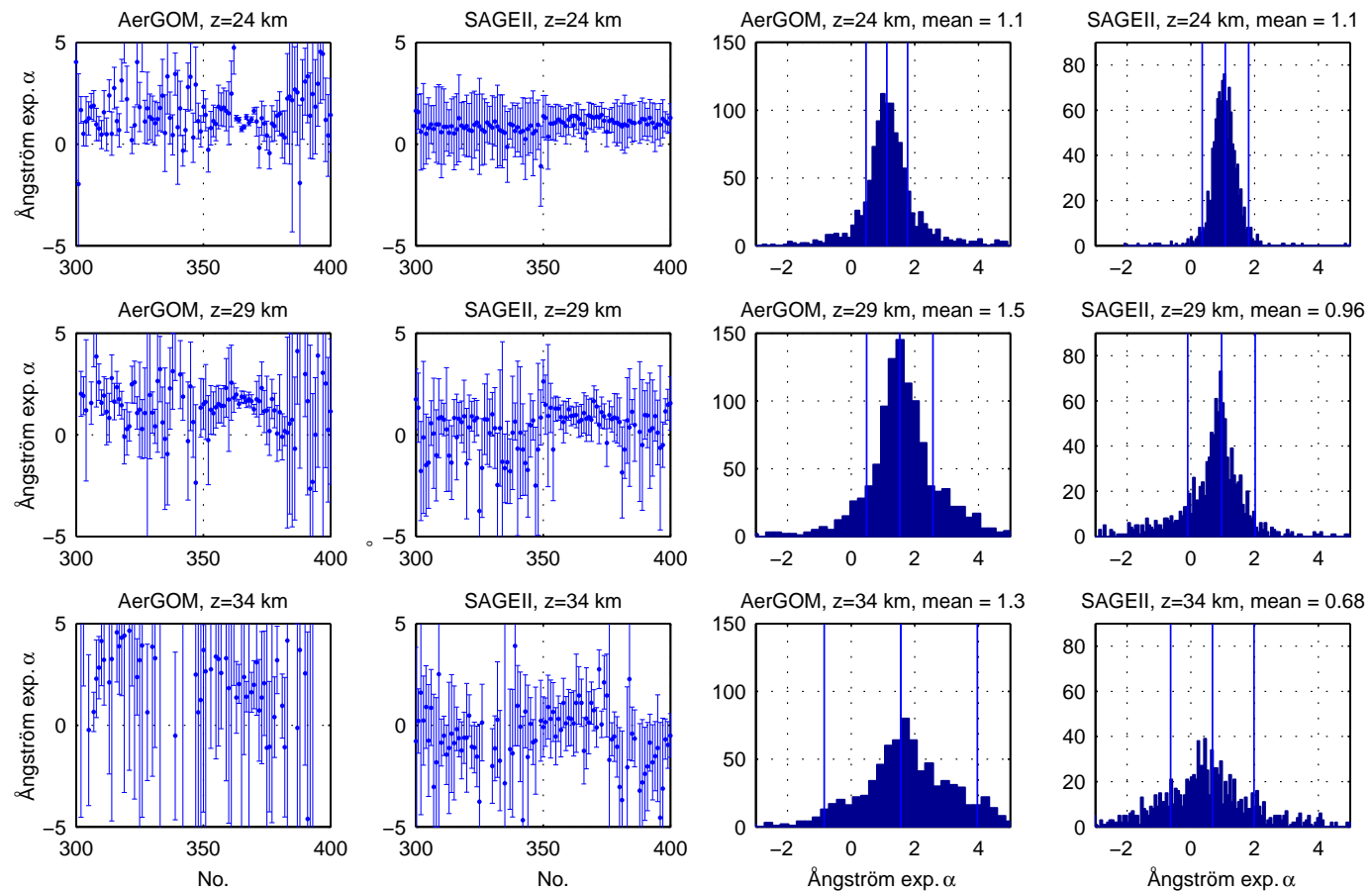

Figure 8. Ångström exponents (AEs) derived from GOMOS-AerGOM and SAGE II data. The same data as for Fig. 7 were used. First two columns: 100 examples of AE for AerGOM and SAGE II at three different altitudes, with error bars. Third and fourth column: AE histograms for the full set of 1152 GOMOS-SAGE II collocations at three different altitudes. Vertical lines represent the error-weighted mean of the distribution (central line), and the median experimental error bars of the AE. The AE weighted mean is also indicated in the subplot titles.

with $A$ a constant and $\alpha$ the Ångström exponent (AE) that describes the spectral shape. The extinction retrieval errors were taken into account. Results are shown in Fig. 8 at three different altitudes. We immediately see that the variability of the $\mathrm{AE}$ is for the most part buried in the experimental error and is therefore statistically not significant. The histograms in the figure for the full GOMOS-SAGE II collocation data set confirm this finding: the statistical spread of the AE distributions falls largely within the limits of the experimental error. The findings are valid for AerGOM as well as SAGE II.

\section{Conclusions}

The GOMOS aerosol extinction profiles produced by the official IPFv6.01 algorithm are of good quality around the $500 \mathrm{~nm}$ reference wavelength, but they show pathological behaviour in other spectral regions. This finding hinted at a conceptual error in the algorithm, instead of a lack of information in the GOMOS data. Within the framework of the AerGOM project, a new algorithm was developed that has some similarities with the IPF code but is equipped with two fundamentally different concepts: an improved aerosol spectral law and a full spatial inversion that does not discard retrieval covariances between species. Additionally, a more accurate Rayleigh scattering cross section and air refractive index has been implemented. The spectral range has been increased by the possibility to use SPB1 and SPB2 spectral measurements (although only SPB1 data have been selected for the first data processing presented in this paper).

The entire GOMOS 10-year mission data set has been processed, and the resulting Level 2 product files (containing altitude profiles for aerosol extinction and gas densities, with error estimates) have been stored as the AerGOM v1.0 data set. An initial inspection of the obtained results shows that the pathological behaviour of the aerosol profiles at wavelengths far from the $500 \mathrm{~nm}$ reference is severely reduced. Furthermore, a coarse comparison of GOMOS-SAGE II colocations shows much better agreement for AerGOMv1.0 than for IPFv6.01 at these wavelengths. Since algorithm development forms the subject of this paper, a detailed validation study of the aerosol extinction product has been presented in a separate companion paper (Robert et al., 2016). Validation of the other products $\left(\mathrm{O}_{3}, \mathrm{NO}_{2}, \mathrm{NO}_{3}\right)$ will be carried out in the future. Finally, it should be mentioned that a new algorithm has been developed for the inversion of aerosol-cloud extinction spectra to particle size distributions. We will also discuss this algorithm in a separate publication.

\section{Data availability}

Data for the AerGOM v1.0 processing version are stored in Network Common Data Form version 4 (NetCDF4) format 
and can be obtained by contacting Christine Bingen (Christine.Bingen@aeronomie.be).

Acknowledgements. The AerGOM project was financed by the European Space Agency (contract number 22022/OP/I-OL). Additional research was supported by a Marie Curie Career Integration Grant within the 7th European Community Framework Programme under grant agreement no. 293560, the European Space Agency within the Aerosol_CCI project of the Climate Change Initiative and the Belgian Space Science Office (BELSPO) through the "Chercheur Supplémentaire" programme.

Edited by: O. Torres

Reviewed by: two anonymous referees

\section{References}

Bates, D.: Rayleigh scattering by air, Planet. Space Sci., 32, 785 790, 1984.

Bauman, J. J., Russell, P. B., Geller, M. A., and Hamill, P.: A stratospheric aerosol climatology from SAGE II and CLAES measurements: 2. Results and comparisons, 1984-1999, J. Geophys. Res., 108, 4383, doi:10.1029/2002JD002993, 2003.

Bernath, P. F., McElroy, C. T., Abrams, M. C., Boone, C. D., Butler, M., Camy-Peyret, C., Carleer, M., Clerbaux, C., Coheur, P.-F., Colin, R., DeCola, P., DeMazière, M., Drummond, J. R., Dufour, D., Evans, W. F. J., Fast, H., Fussen, D., Gilbert, K., Jennings, D. E., Llewellyn, E. J., Lowe, R. P., Mahieu, E., McConell, J. C., McHugh, M., McLeod, S. D., Michaud, R., Midwinter, C., Nassar, R., Nichitiu, F., Nowlan, C., Rinsland, C. P., Rochon, Y. J., Rowlands, N., Semeniuk, K., Simon, P., Skelton, R., Sloan, J. J., Soucy, M. A., Strong, K., Tremblay, P., Turnbull, D., Walker, K. A., Walkty, I., Wardle, D. A., Wehrle, V., Zander, R., and Zou, J.: Atmospheric Chemistry Experiment (ACE): Mission overview, Geophys. Res. Lett., 32, L15S01, doi:10.1029/2005GL022386, 2005.

Bertaux, J., Kyrölä, E., and Wehr, T.: Stellar occultation technique for atmospheric ozone monitoring: GOMOS on Envisat, Earth Obs. Quarterly, 67, 17-20, 2000.

Bertaux, J. L., Kyrölä, E., Fussen, D., Hauchecorne, A., Dalaudier, F., Sofieva, V., Tamminen, J., Vanhellemont, F., Fanton d'Andon, O., Barrot, G., Mangin, A., Blanot, L., Lebrun, J. C., Pérot, K., Fehr, T., Saavedra, L., Leppelmeier, G. W., and Fraisse, R.: Global ozone monitoring by occultation of stars: an overview of GOMOS measurements on ENVISAT, Atmos. Chem. Phys., 10, 12091-12148, doi:10.5194/acp-10-12091-2010, 2010.

Bodhaine, B. A., Wood, N. B., Dutton, E. G., and Slusser, J. R.: On Rayleigh Optical Depth Calculations, J. Atmos. Ocean. Tech., 16, 1854-1861, 1999.

Carslaw, K. S., Peter, T., and Clegg, S. L.: Modeling the composition of liquid stratospheric aerosols, Rev. Geophys., 35, 125-154, 1997.

Chu, W., McCormick, M., Lenoble, J., Brogniez, C., and Pruvost, P.: SAGE II inversion algorithm, J. Geophys. Res., 94, 8339-8351, 1989.

Deshler, T., Hervig, M. E., Hofmann, D. J., Rosen, J. M., and Liley, J. B.: Thirty years of in situ stratospheric aerosol size distribution measurements from Laramie, Wyoming $\left(41^{\circ} \mathrm{N}\right)$, using balloon-borne instruments, J. Geophys. Res., 108, 4167, doi:10.1029/2002JD002514, 2003.

Edlén, B.: The refractive index of air, Metrologia, 2, 71-80, 1966.

Fussen, D., Vanhellemont, F., and Bingen, C.: Remote Sensing of the Earth's atmosphere by the spaceborne Occultation Radiometer, ORA: final inversion algorithm, Appl. Optics, 40, 941-948, 2001.

Fussen, D., Vanhellemont, F., and Bingen, C.: Optimal spectral inversion of atmospheric radiometric measurements in the nearUV to near-IR range: A case study, Opt. Express, 10, 70-82, 2002.

Krieger, U. K., Mössinger, J. C., Luo, B., Weers, U., and Peter, T.: Measurement of the refractive indices of $\mathrm{H}_{2} \mathrm{SO}_{4}-\mathrm{HNO}_{3}-\mathrm{H}_{2} \mathrm{O}$ solutions to stratospheric temperatures, Appl. Optics, 39, 36913703, 2000.

Kyrölä, E., Tamminen, J., Leppelmeier, G., Sofieva, V., Hassinen, S., Bertaux, J., Hauchecorne, A., Dalaudier, F., Cot, C., Korablev, O., Fanton d'Andon, O., Barrot, G., Mangin, A., Theodore, B., Guirlet, M., Etanchaud, F., Snoeij, P., Koopman, R., Saavedra, L., Fraisse, R., Fussen, D., and Vanhellemont, F.: GOMOS on Envisat - an overview, Adv. Space Res., 33, 1020-1028, 2004.

Kyrölä, E., Tamminen, J., Sofieva, V., Bertaux, J. L., Hauchecorne, A., Dalaudier, F., Fussen, D., Vanhellemont, F., Fanton d'Andon, O., Barrot, G., Guirlet, M., Mangin, A., Blanot, L., Fehr, T., Saavedra de Miguel, L., and Fraisse, R.: Retrieval of atmospheric parameters from GOMOS data, Atmos. Chem. Phys., 10, 1188111903, doi:10.5194/acp-10-11881-2010, 2010.

Kyrölä, E., Blanot, L., Tamminen, J., Sofieva, V., Bertaux, J.-L., Hauchecorne, A., Dalaudier, F., Fussen, D., Vanhellemont, F., Fanton d'Andon, O., and Barrot, G.: GOMOS-Algorithm Theoretical Basis Document, version 3.0, Tech. rep., ESA, 2012.

Lenoble, J.: Atmospheric Radiative Transfer - Studies in Geophysical Optics and Remote Sensing, A. Deepak Publishing, Hampton, VA, USA, 1993.

Lucke, R. L., Korwan, D. R., Bevilacqua, R., Hornstein, J. S., Shettle, E. P., Chen, D. T., Daehler, M., Lumpe, J. D., Fromm, M. D., Debrestian, D., Neff, B., Squire, M., König-Langlo, G., and Davies, J.: The Polar Ozone and Aerosol Measurement (POAM) III instrument and early validation results, J. Geophys. Res., 104, 18785-18799, 1999.

Lumpe, J. D., Bevilacqua, R. M., Hoppel, K. W., and Randall, C. E.: POAM III retrieval algorithm and error analysis, J. Geophys. Res.-Atmos, 107, 4575, doi:10.1029/2002JD002137, 2002.

McElroy, C. T., Nowlan, C. R., Drummond, J. R., Bernath, P. F., Barton, D. V., Dufour, D. G., Midwinter, C., Hall, R. B., Ogyu, A., Ullberg, A., Wardle, D. I., Kar, J., Zou, J., Nichitiu, F., Boone, C. D., Walker, K. A., and Rowlands, N.: The ACE-MAESTRO instrument on SCISAT: description, performance, and preliminary results, Appl. Optics, 46, 4341-4356, 2007.

Meilinger, S. K., Koop, T., Luo, B. P., Huthwelker, T., Carslaw, K. S., Krieger, U., Crutzen, P. J., and Peter, T.: Size-dependent stratospheric droplet composition in leewave temperature fluctuations and their potential role in PSC freezing, Geophys. Res. Lett., 22, 3031-3034, 1995.

NIMA: World Geodetic System 1984, Its Definition and Relationships With Local Geodetic Systems, Technical Report TR8350.2, Department of Defense, 1984. 
Peck, E. R. and Reeder, K.: Dispersion of air, JJ. Opt. Soc. Am., 62, 958-962, 1972.

Pueschel, R., Russell, P., Allen, D., Ferry, G., Snetsinger, K., Livingston, J., and Verma, S.: Physical and optical properties of the Pinatubo volcanic aerosol: aircraft observations with impactors and a Sun-tracking photometer, J. Geophys. Res., 99, 1291512922, 1994.

Robert, C. É., Bingen, C., Vanhellemont, F., Mateshvili, N., Dekemper, E., Tétard, C., Fussen, D., Bourassa, A., and Zehner, C.: AerGOM, an improved algorithm for stratospheric aerosol extinction retrieval from GOMOS observations - Part 2: Intercomparisons, Atmos. Meas. Tech., 9, 4701-4718, doi:10.5194/amt9-4701-2016, 2016.

Sofieva, V. F., Kan, V., Dalaudier, F., Kyrölä, E., Tamminen, J., Bertaux, J.-L., Hauchecorne, A., Fussen, D., and Vanhellemont, F.: Influence of scintillation on quality of ozone monitoring by GOMOS, Atmos. Chem. Phys., 9, 9197-9207, doi:10.5194/acp9-9197-2009, 2009.

Sofieva, V. F., Vira, J., Kyrölä, E., Tamminen, J., Kan, V., Dalaudier, F., Hauchecorne, A., Bertaux, J.-L., Fussen, D., Vanhellemont, F., Barrot, G., and Fanton d'Andon, O.: Retrievals from GOMOS stellar occultation measurements using characterization of modeling errors, Atmos. Meas. Tech., 3, 1019-1027, doi:10.5194/amt-3-1019-2010, 2010.

SPARC: Report no. 4: Assessment of Stratospheric Aerosol Properties (ASAP), edited by: Thomason, L. and Peter, T., Report WCRP-124 / WMO/TD-No. 1295, WMO/ICSU/IOC World Climate Research Programme, http://www.sparc-climate.org/ publications/sparc-reports/, 2006.

Stefanutti, L., MacKenzie, A. R., Santacesaria, V., Adriani, A., Balestri, S., Borrmann, S., Khattatov, V., Mazzinghi, P., Mitev, V., Rudakov, V., Schiller, C., Toci, G., Volk, C. M., Yushkov, V., Flentje, H., Kiemle, C., Redaelli, G., Carslaw, K. S., Noone, K., and Peter, T.: The APE-THESEO Tropical Campaign: An Overview, J. Atmos. Chem., 48, 1-33, doi:10.1023/B:JOCH.0000034509.11746.b8, 2004.

Tamminen, J., Kyrölä, E., Sofieva, V. F., Laine, M., Bertaux, J.-L., Hauchecorne, A., Dalaudier, F., Fussen, D., Vanhellemont, F., Fanton-d'Andon, O., Barrot, G., Mangin, A., Guirlet, M., Blanot, L., Fehr, T., Saavedra de Miguel, L., and Fraisse, R.: GOMOS data characterisation and error estimation, Atmos. Chem. Phys., 10, 9505-9519, doi:10.5194/acp-10-9505-2010, 2010.
Thomason, L. W., Poole, L. R., and Randall, C. E.: SAGE III aerosol extinction validation in the Arctic winter: comparisons with SAGE II and POAM III, Atmos. Chem. Phys., 7, 14231433, doi:10.5194/acp-7-1423-2007, 2007.

Thomason, L. W., Moore, J. R., Pitts, M. C., Zawodny, J. M., and Chiou, E. W.: An evaluation of the SAGE III version 4 aerosol extinction coefficient and water vapor data products, Atmos. Chem. Phys., 10, 2159-2173, doi:10.5194/acp-10-2159-2010, 2010.

Vanhellemont, F., Fussen, D., Bingen, C., Kyrölä, E., Tamminen, J., Sofieva, V., Hassinen, S., Verronen, P., Seppälä, A., Bertaux, J. L., Hauchecorne, A., Dalaudier, F., Fanton d'Andon, O., Barrot, G., Mangin, A., Theodore, B., Guirlet, M., Renard, J. B., Fraisse, R., Snoeij, P., Koopman, R., and Saavedra, L.: A 2003 stratospheric aerosol extinction and PSC climatology from GOMOS measurements on Envisat, Atmos. Chem. Phys., 5, 2413-2417, doi:10.5194/acp-5-2413-2005, 2005.

Vanhellemont, F., Fussen, D., Dodion, J., Bingen, C., and Mateshvili, N.: Choosing a suitable analytical model for aerosol extinction spectra in the retrieval of UV/visible satellite occultation measurements, J. Geophys. Res., 111, D23203, doi:10.1029/2005JD006941, 2006.

Vanhellemont, F., Tetard, C., Bourassa, A., Fromm, M., Dodion, J., Fussen, D., Brogniez, C., Degenstein, D., Gilbert, K. L., Turnbull, D. N., Bernath, P., Boone, C., and Walker, K. A.: Aerosol extinction profiles at $525 \mathrm{~nm}$ and $1020 \mathrm{~nm}$ derived from ACE imager data: comparisons with GOMOS, SAGE II, SAGE III, POAM III, and OSIRIS, Atmos. Chem. Phys., 8, 2027-2037, doi:10.5194/acp-8-2027-2008, 2008.

Vanhellemont, F., Fussen, D., Mateshvili, N., Tétard, C., Bingen, C., Dekemper, E., Loodts, N., Kyrölä, E., Sofieva, V., Tamminen, J., Hauchecorne, A., Bertaux, J.-L., Dalaudier, F., Blanot, L., Fanton d'Andon, O., Barrot, G., Guirlet, M., Fehr, T., and Saavedra, L.: Optical extinction by upper tropospheric/stratospheric aerosols and clouds: GOMOS observations for the period 2002 2008, Atmos. Chem. Phys., 10, 7997-8009, doi:10.5194/acp-107997-2010, 2010.

Warren, S. G.: Optical constants of ice from the ultraviolet to the microwave, Appl. Optics, 23, 1206-1225, 1984. 